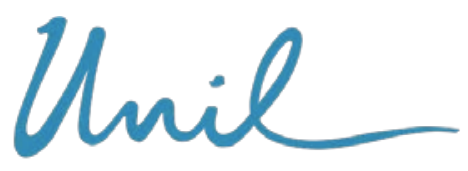

UNIL | Université de Lausanne

Unicentre

$\mathrm{CH}-1015$ Lausanne

http://serval.unil.ch

Year : 2016

\title{
Laser supraglottoplasty for laryngomalacia: a 14 year experience of a tertiary referral center
}

\author{
Reinhard Antoine
}

Reinhard Antoine, 2016, Laser supraglottoplasty for laryngomalacia: a 14 year experience of a tertiary referral center

Originally published at : Thesis, University of Lausanne

Posted at the University of Lausanne Open Archive http://serval.unil.ch

Document URN : urn: nbn:ch: serval-BIB_46B3F2DF2FC47

\section{Droits d'auteur}

L'Université de Lausanne attire expressément l'attention des utilisateurs sur le fait que tous les documents publiés dans l'Archive SERVAL sont protégés par le droit d'auteur, conformément à la loi fédérale sur le droit d'auteur et les droits voisins (LDA). A ce titre, il est indispensable d'obtenir le consentement préalable de l'auteur et/ou de l'éditeur avant toute utilisation d'une oeuvre ou d'une partie d'une oeuvre ne relevant pas d'une utilisation à des fins personnelles au sens de la LDA (art. 19, al. 1 lettre a). A défaut, tout contrevenant s'expose aux sanctions prévues par cette loi. Nous déclinons toute responsabilité en la matière.

\section{Copyright}

The University of Lausanne expressly draws the attention of users to the fact that all documents published in the SERVAL Archive are protected by copyright in accordance with federal law on copyright and similar rights (LDA). Accordingly it is indispensable to obtain prior consent from the author and/or publisher before any use of a work or part of a work for purposes other than personal use within the meaning of LDA (art. 19, para. 1 letter a). Failure to do so will expose offenders to the sanctions laid down by this law. We accept no liability in this respect. 
UNIL | Université de Lausanne

\title{
FACULTÉ DE BIOLOGIE ET DE MEDECINE \\ DEPARTEMENT DE CHIRURGIE SERVICE D'OTO-RHINO-LARYNGOLOGIE
}

\author{
Laser supraglottoplasty for \\ laryngomalacia : a 14 year \\ experience of a tertiary \\ refferal center
}

\section{THĖSE DE DOCTORAT}

présentée à la

Faculté de médecine de I'Université de Lausanne

pour l'obtention du grade de

Docteur en médecine

$$
\text { par }
$$

Antoine Reinhard

Directeur de thèse (Dr Kishore Sandu)

[Co-directeur de thèse] [(Prof. Christian Simon)]

$$
\text { [Jury] }
$$

[Prof John Prior]

LAUSANNE

(2016) 
UNIVERSITE DE LAUSANNE - FACULTE DE BIOLOGIE ET DE MEDECINE

Département de chirurgie

Service d'oto-rhino-laryngologie et chirurgie cervico-faciale

Laser supraglottoplasty for laryngomalacia: a 14 year experience of a tertiary referral center

\section{THESE}

préparée sous la direction du Docteur Kishore Sandu

(avec la co-direction du Professeur Christian Simon)

et présentée à la Faculté de biologie et de médecine de

l'Université de Lausanne pour l'obtention du grade de

DOCTEUR EN MEDECINE

par

Antoine REINHARD

Médecin diplômé de la Confédération Suisse

Originaire de Rüttenen (SO)

Lausanne

2016 


\section{Unil}

UNIL | Université de Lausanne

Faculté de biologie

et de médecine

Ecole Doctorale

Doctorat en médecine

\section{Imprimatur}

Vu le rapport présenté par le jury d'examen, composé de

Directeur de thèse Monsieurle Docteur Kishore SANDU

Co-Directeur de thèse Monsieur le Professeur Cristian Simon

Expert

Vice-Directeur de

l'Ecole doctorale

Monsieur Le Professeur John Prior

la Commission MD de l'Ecole doctorale autorise l'impression de la thèse de

\section{Monsieur Antoine REINHARD}

intitulée

Laser Supraglottoplasty for laryngomalacia: a 14 year experience of a tertiary referral center

Lausanne, le 26 septembre 2016

pour Le Doyen

de la Faculté de Biologie et de Médecine

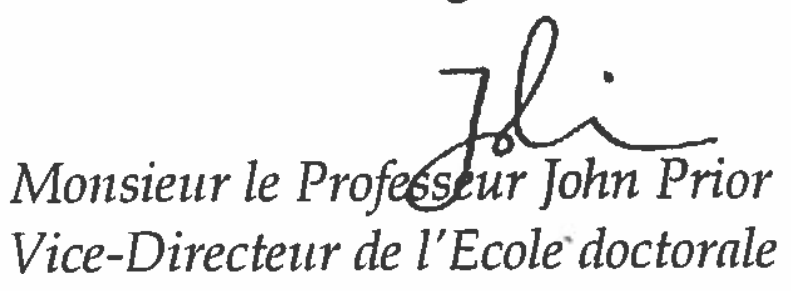




\section{Résumé de thèse en français}

\section{Titre :}

Supraglottoplastie au laser pour les laryngomalacies : 14 ans d'expérience d'un centre de référence tertiaire

\section{Objectifs :}

Analyser les résultats des supraglottoplasties au laser effectuées chez des enfants présentant une laryngomalacie symptomatique et déterminer les facteurs qui les influencent.

\section{Méthode :}

Analyse rétrospective des données médicales de patients ayant bénéficié d'une supraglottoplastie au laser CO2 pour une laryngomalacie symptomatique au CHUV entre novembre 2001 et novembre 2014. Analyser la démographie, les symptômes, les comorbidités, le type de laryngomalacie et les résultats après supraglottoplastie au laser.

\section{Résultats :}

79 patients ont été inclus dans l'étude. L'âge médian lors de la chirurgie était de 12.7 mois. $55.7 \%$ des cas présentaient des comorbidités associées, $22.8 \%$ étaient prématurés et des lésions synchrones des voies aériennes étaient présentes dans 32.9\% des cas. Les différents types morphologiques de laryngomalacie (I, II, III) étaient rencontrés dans $26.6 \%, 62 \%$ et $11.4 \%$ des patients respectivement. Le taux de succès des supraglottoplasties était de $86.1 \%$. On notait 11 échecs $(13.9 \%)$ sur 79 cas ayant nécessité 15 procédures de révision. Le taux de succès chez les patients présentant des comorbidités, des lésions synchrones des voies aériennes, des pathologies neurologiques et une prématurité était de $81.8 \%, 76.9 \%, 69.2 \%$ et $66.7 \%$ respectivement. Les patients avec une laryngomalacie de type III avaient un taux limité de succès (66.7\%) comparé aux patients avec un type morphologique I et II $(90.5 \%$ et $87.8 \%$ respectivement).

\section{Conclusion :}

La supraglottoplastie au laser est un traitement sûre et efficace pour les laryngomalacies symptomatiques. Les patients avec une prématurité, une laryngomalacie de type III, des lésions synchrones des voies aériennes et des comorbidités associées sont prédisposés à des échecs chirurgicaux. 


\section{Laser supraglottoplasty for laryngomalacia; a 14 year experience of a tertiary referral center}

\section{Antoine Reinhard, François Gorostidi, Crispin Leishman, Philippe Monnier \& Kishore Sandu}

European Archives of Oto-RhinoLaryngology and Head \& Neck

ISSN 0937-4477

Eur Arch Otorhinolaryngol DOI 10.1007/s00405-016-4252-6

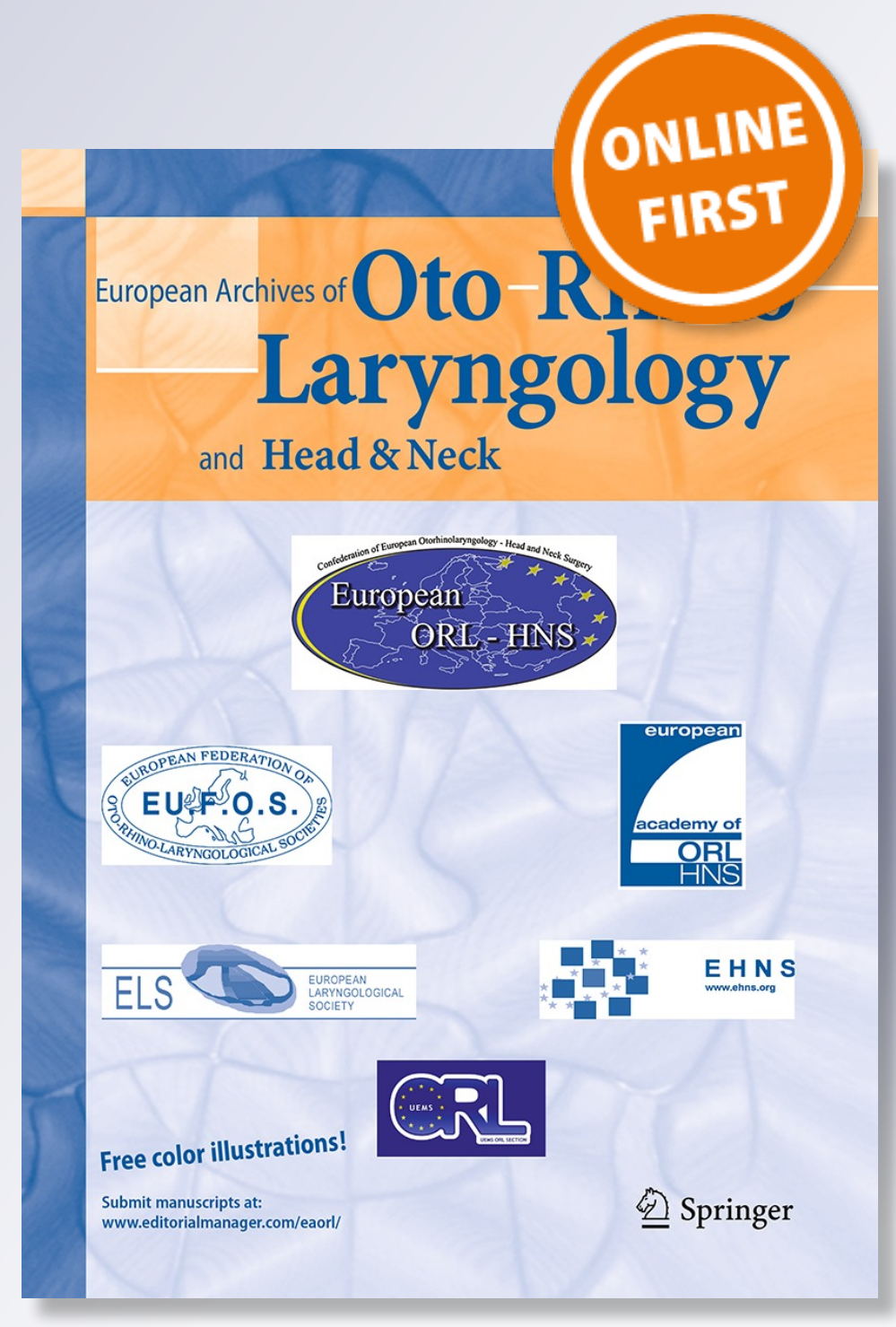

\section{照 Springer}


Your article is protected by copyright and all rights are held exclusively by SpringerVerlag Berlin Heidelberg. This e-offprint is for personal use only and shall not be selfarchived in electronic repositories. If you wish to self-archive your article, please use the accepted manuscript version for posting on your own website. You may further deposit the accepted manuscript version in any repository, provided it is only made publicly available 12 months after official publication or later and provided acknowledgement is given to the original source of publication and a link is inserted to the published article on Springer's website. The link must be accompanied by the following text: "The final publication is available at link.springer.com". 


\title{
Laser supraglottoplasty for laryngomalacia; a 14 year experience of a tertiary referral center
}

\author{
Antoine Reinhard ${ }^{1} \cdot$ François Gorostidi $^{1} \cdot$ Crispin Leishman $^{1} \cdot$ Philippe Monnier $^{1}$. \\ Kishore Sandu ${ }^{1}$
}

Received: 12 July 2016/ Accepted: 7 August 2016

(c) Springer-Verlag Berlin Heidelberg 2016

\begin{abstract}
To review the outcomes of laser supraglottoplasty performed in children with symptomatic laryngomalacia and determine the factors influencing them. We retrospectively reviewed the medical records of patients who underwent laser supraglottoplasty for symptomatic laryngomalacia at the Lausanne University Hospital from November 2001 to November 2014. We examined the patient's demography, symptoms, comorbidities, type of laryngomalacia, synchronous airway lesions, and final outcomes. Seventy-nine patients were included in this study; median age at the time of surgery was 12.7 months. $55.7 \%$ of the cases had comorbidities, $22.8 \%$ of the patients were premature and synchronous airway lesions were present in $32.9 \%$ of the cases. The different morphological types of laryngomalacia (I-III) were seen in 26.6, 62 and $11.4 \%$ of the patients, respectively. Overall, operation specific success rate of laser supraglottoplasty was $86.1 \%$. Failures in $11(13.9 \%)$ of the 79 cases required 15 revision procedures. Success rates for patients with associated comorbidities, synchronous airway lesions, neurological disorders and prematurity were 81.8, 76.9, 69.2 and $66.7 \%$, respectively. Patients with type III laryngomalacia had a limited success rate $(66.7 \%)$ as compared to patients with morphological types I and II ( 90.5 and $87.8 \%$, respectively). Laser supraglottoplasty is an effective and safe treatment for symptomatic laryngomalacia. Patients with prematurity, type III LM,
\end{abstract}

Antoine Reinhard

antoine.reinhard@chuv.ch

1 Department of Otorhinolaryngology, Centre Hospitalier Universitaire Vaudois, Rue du Bugnon 21, 1011 Lausanne, Switzerland synchronous airway lesions and associated comorbidities are predisposed to surgical failure.

Keywords Laryngomalacia - Laser - Supraglottoplasty · Pediatric airway $\cdot$ Stridor

\section{Introduction}

Laryngomalacia (LM) is the most common cause of stridor in infants and represents almost $60-70 \%$ of all congenital laryngeal anomalies [1]. It is characterized by a dynamic obstruction of the upper airway caused by an inward collapse of supraglottic structures during inspiration resulting in an inspiratory stridor [2]. The exact pathophysiology of LM remains unclear, and several theories have been proposed to explain its etiology [3-5]. The neurological theory, which is actually the most widely accepted, suggests a neurosensory dysfunction leading to poor neuromuscular coordination of the supraglottic airway. This theory comes from the observation of increased laryngopharyngeal sensory thresholds in patients with LM [5], indicating that peripheral afferent function of laryngeal sensation is altered. Gastroesophageal reflux disease (GERD) has also been suspected to cause LM as GERD is observed in about $70-80 \%$ of cases [6]. The proposed mechanism indicating the role of GERD results secondarily from an increased negative pressure needed to overcome the upper airway obstruction caused by LM. However, a systematic review of the literature has not found a direct causal relationship between the two entities [7].

Several classifications of LM have been proposed depending on the subsite of laryngeal involvement [2, 8-12], but none have been universally adopted. Olney and colleagues described three types of LM depending on 
the supraglottic morphology [9]. Type I is characterized by prolapsing supra arytenoid floppy tissues, type II by shortened aryepiglottic folds associated with a long tubular epiglottis that curls on itself and type III by an overhanging retroflexed epiglottis that collapses posteriorly during inspiration (Fig. 1).

Symptoms usually appear within the first weeks of life, progress to a peak around 2-5 months and resolve before 2 years of age [5, 13]. LM induced inspiratory stridor typically gets worse during increased air demands. Ten to $20 \%$ of cases present with severe symptoms requiring endoscopic supraglottplasty (SGP) $[5,14,15]$. The indicators of severe LM requiring surgical correction are: stridor with dyspnea and suprasternal/intercostal retractions, hypoxia, apneic spells, recurrent cyanosis, feeding difficulties with failure to thrive and cor pulmonale $[4,8]$. The success rate of SGP varies between 60 and $95 \%[8,10,16]$, with patients suffering from comorbidities such as congenital anomalies, neurologic pathologies, prematurity and obesity having poorer outcomes [17-22].

In case of severe LM, a systematic dynamic airway endoscopy is required to confirm the clinical diagnosis, characterize the morphological type of LM, rule out other associated anomalies and decide the kind of SGP that needs to be performed. Diagnosis and surgical correction of LM are performed during the same general anesthesia.

In this article, we review the outcomes of laser supraglottoplasty (LSGP) performed at a tertiary referral center for children with severe symptomatic LM, and we discuss the factors influencing these outcomes.

\section{Materials and methods}

After institutional review board approval, we retrospectively analyzed the medical records of patients who underwent LSGP for symptomatic LM at the Lausanne University Hospital from November 2001 to November 2014. The diagnosis of LM was based on clinical presentation and confirmed by a transnasal fiberoptic laryngoscopy (TNFL) under general anesthesia and the patient breathing spontaneously allowing a dynamic upper airway evaluation. Flexible bronchoscopy, rigid laryngo-tracheoscopy and oesophagoscopy were performed during the same procedure to rule out synchronous upper airway and reflux-induced lesions. The supraglottic obstruction was classified according to Olney's classification [9] to determine the morphological type of LM (Fig. 1).

Indications for LSGP were: severe LM with inspiratory stridor, dyspnea with chest retractions, oxygen desaturations, cyanosis, obstructive apneas, feeding difficulties with or without failure to thrive and presence of a tracheostomy due to severe laryngomalacia. All LSGP were performed by senior surgeons under general anesthesia and successive apnea technique. The larynx was exposed by a suspension laryngoscope (Benjamin-Lindholm laryngoscope, Storz, Germany) inserted into the valleculae permitting an axial, panoramic and symmetrical exposure of the supraglottic structures. Intermittent translaryngeal intubation was done through the suspension laryngoscope by inserting 3.0/3.5 portex blue line endotracheal tube with the help of laryngeal forceps under direct vision. The procedure was performed using the $\mathrm{CO}_{2}$ laser (Ultra Pulse Surgi Touch $\mathrm{CO}_{2}$ laser, Lumenis, Israel) connected to a microscope (Leica, Germany) and a micro-

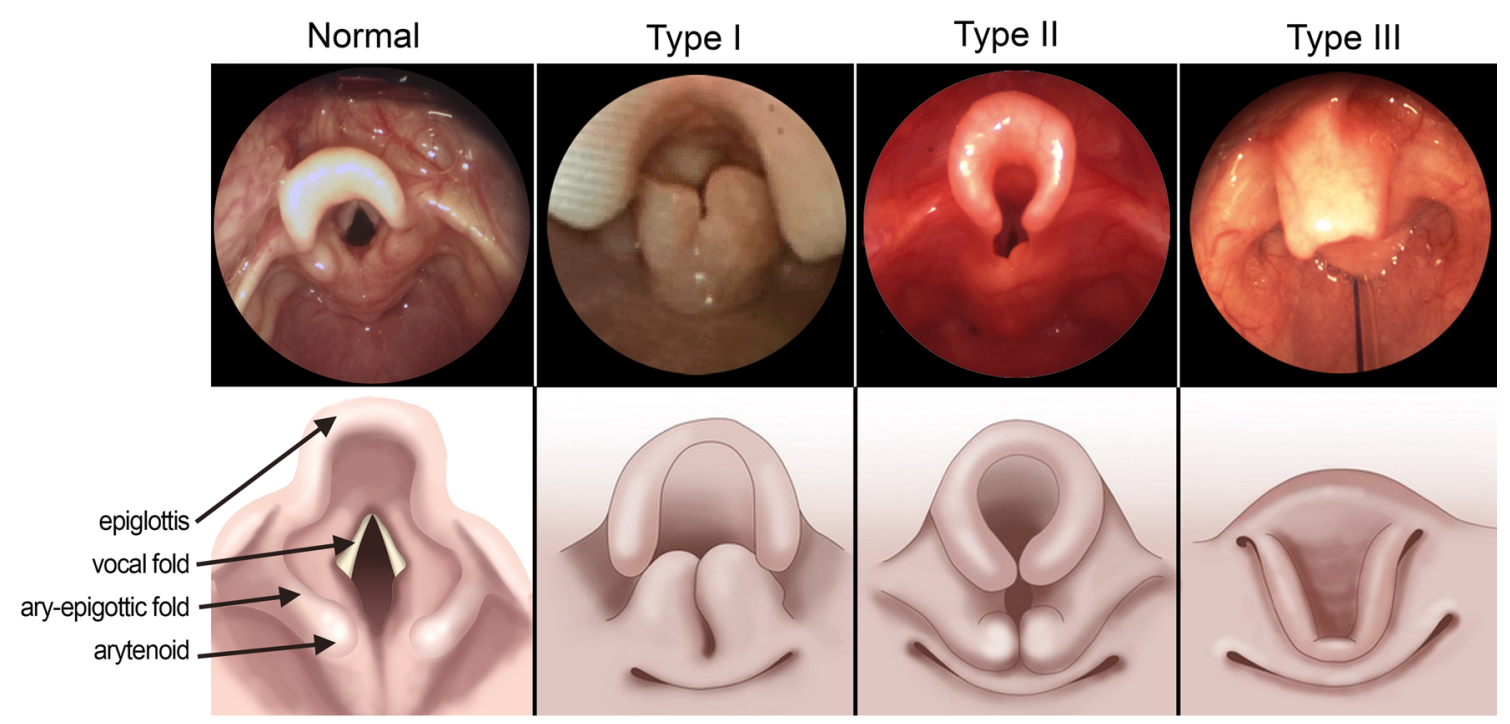

Fig. 1 Morphological types of laryngomalacia (LM) classified according to Olney's classification: Type I LM: prolapsing supra arytenoid floppy tissues, Type II LM: shortened aryepiglottic folds associated with a long, omega-shape epiglottis that curls on itself, Type III LM: overhanging retroflexed epiglottis collapsing posteriorly during inspiration 
manipulator (Clearspot $160 / 400 \mathrm{~mm}$, Coherent, USA) allowing a very precise and bloodless resection. The laser parameters used were: ultrapulse mode, $125 \mathrm{~mJ} / \mathrm{cm}^{2}$ and 250 microspot. In type I LM, the excess floppy arytenoid mucosa, corniculate and cuneiform cartilages were partially resected and/or vaporized. For type II LM, the shortened aryepiglottic folds were sectioned and the lateral edges of the epiglottis resected. In addition, floppy supraglottic tissues were partially resected and/or vaporized (Fig. 2).

Endoscopic epiglottopexy was performed for type III LM. This consisted of using the $\mathrm{CO}_{2}$ laser (continuous working mode, 3 Watts) and performing mucosal fulguration of the tongue base, valleculae and lingual aspect of the epiglottis. The epiglottopexy was done by passing two or three transoral resorbable sutures (3.0 Vicryl) through the epiglottis and as deep as possible into the musculature of the tongue base (Fig. 3).

We noted patients demography, pre- and post-operative symptoms, clinical signs, comorbidities (neurologic, prematurity, synchronous airway lesions SAL, GERD), morphological types of LM, type of SGP performed, duration of stay in intensive care unit, total hospital stay, complications and finally the necessity and type of revision surgery, if performed.

Operation specific success rate (OSSR) was defined as complete resolution of the initial symptoms or definitive symptom improvement without the need for further intervention. Failure was defined as insufficient improvement of the initial symptoms requiring further intervention (revision surgery, prolonged non-invasive ventilation and oxygen therapy, tracheotomy). Statistical analysis was done using the Fisher's exact test.

\section{Results}

Seventy-nine patients were included in this study. There were 44 boys $(55.7 \%)$ and 35 girls $(44.3 \%)$, and the mean age of performing SGP was 12.7 months (m) (range
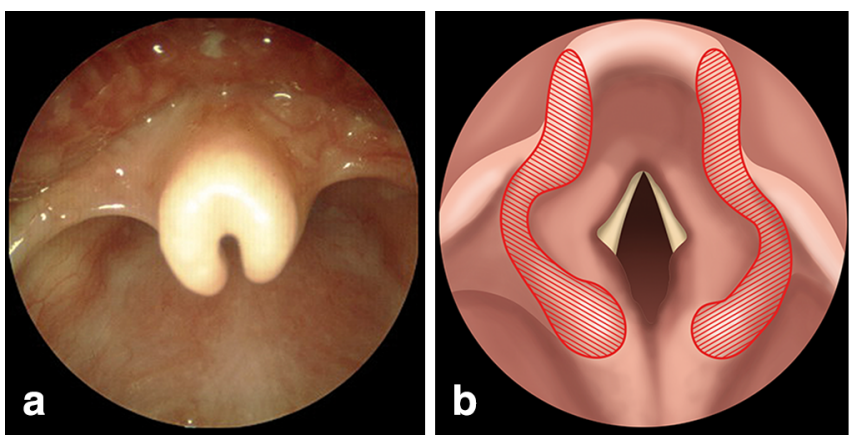

Fig. 2 Laser supraglottoplasty LSGP for type II laryngomalacia: a pre-operative view: curled, tubular epiglottis. b Schematic diagram showing laser resection of short aryepiglottic folds and trimming of the lateral edges of the epiglottis. $\mathbf{c}$ Endoscopic view after $\mathrm{CO}_{2}$ laser
1-137 m). The most common presenting symptoms and indications for SGP were stridor $(93.7 \%)$, chest retractions $(69.6 \%)$, feeding difficulties/failure to thrive $(43 \%)$ and desaturations/cyanosis/apnea $(27.8 \%)$. Five patients $(6.3 \%)$ were already tracheotomised and transferred to our hospital for further management. The morphological types of LM I-III were seen in 26.6, 62 and $11.4 \%$ patients, respectively. Post-surgery extubation was possible in the operating theater in $82.3 \%$ of cases. With increasing experience of our team, we observed that it is almost always possible to extubate the patient in the operating theater (54 of the last 56 consecutive cases) provided that no major comorbidities are present. All patients were transferred to the intensive care unit with continuous positive airway pressure (CPAP) that was gradually weaned off. The mean duration of stay in the intensive care unit was $45.4 \mathrm{~h}(\mathrm{~h})(0-360 \mathrm{~h})$ and the mean hospital stay was 7.78 days (d) (1-130 days).

Surgical complications occurred in six patients (7.6\%): three patients experienced a complete breakdown after epiglottopexy with relapse of type III LM (all three patients had a revision epiglottopexy with good results), two patients presented with poor healing and scar tissue formation between the free edge of the epiglottis and the pharyngo-epiglottic folds after LSGP for type II LM (both patients had minimal feeding difficulties that improved over time) and one patient developed subglottic stenosis due to prolonged intubation after post-operative pneumonia. This patient underwent a partial cricotracheal resection with a favorable outcome.

LSGP outcomes were as follows: $73.4 \%$ of patients had complete resolution of their initial symptoms, $16.5 \%$ of patients had improvement and $10.1 \%$ had persistence of initial symptoms with a mean follow up of 4.7 months (m) (range 1-39 m). Operation specific success rate (OSSR) for all patients was $86.1 \%$ (68/79 patients). Eleven patients underwent one or more revision surgeries (total 15 revision procedures). Revision procedures were
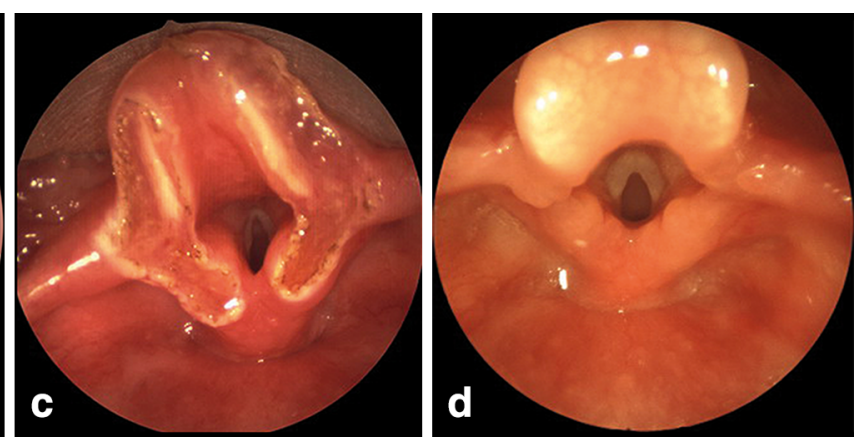

resection. Note that the pharyngo-epiglottic folds and the posterior commissure are untouched. d Post-operative view 3 months after LSGP 

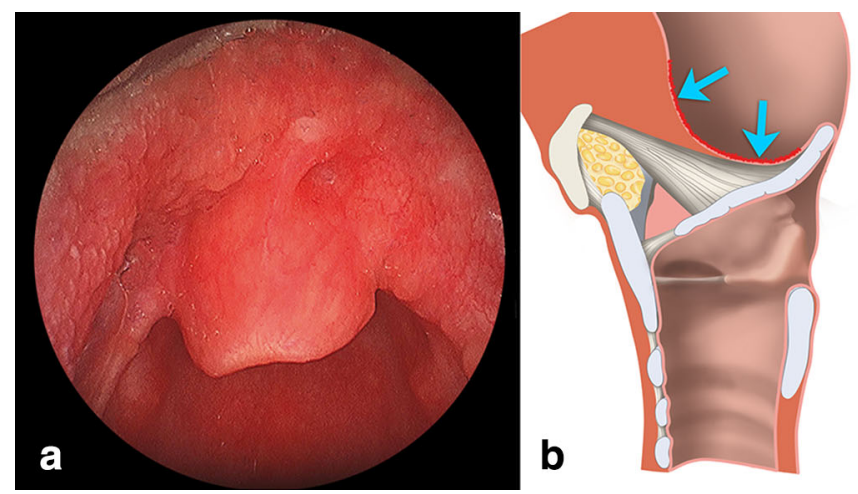

Fig. 3 Supraglottoplasty for type III laryngomalacia (epiglottopexy): a pre-operative endoscopic view demonstrating laryngeal inlet obstruction by a prolapsing retroflexed epiglottis (type III LM). b Schematic diagram showing the target area (red line and blue

LSGP (four patients with type I LM and two patients with type II LM) and epiglottopexy in nine patients. After revision surgery, five patients had complete resolution of their symptoms, five had significant improvement and one had persistence of his symptoms.

Forty-four patients $(55.7 \%)$ had associated comorbidities: 13 patients $(16.5 \%)$ had neurological comorbidities, 26 patients $(32.9 \%)$ patients had SAL, 18 patients $(22.8 \%)$ were born prematurely and 33 patients $(41.8 \%)$ suffered from severe GERD.

Operation specific success rates (OSSR) for the different types of LM (type I-III) were $90.5 \%$ (19/21), $87.8 \%$ (43/ $49)$ and $66.7 \%(6 / 9)$, respectively. The OSSR for patients with comorbidities was $81.8 \%(36 / 44)$ as compared to $91.4 \%(32 / 35)$ for patients without comorbidities. OSSR for patients with comorbidities was $66.7 \%(12 / 18)$ in premature patients, $69.2 \%(9 / 13)$ in patients with neurological comorbidities, $76.9 \%(20 / 26)$ in patients with SAL and $78.8 \%(26 / 33)$ in patients with GERD. Using onesided Fisher's exact test to evaluate the OSSR after LSGP, the only factor that showed statistical significance was prematurity $(p=0.014)$ (Table 1$)$.

When patients were analyzed according to the morphological type of LM (Table 2): the mean age at the time of LSGP was 21.9 months (m) (range 0-131 m) for type I, $4.8 \mathrm{~m}(0-28 \mathrm{~m})$ for type II and $34.7 \mathrm{~m}(3-137 \mathrm{~m})$ for type III. Five out of $9(55.6 \%)$ patients with type III LM were tracheostomised before being referred to us for further treatment, as compared to none with types I or II. Duration of hospital stay was 11.11 days (d) (range 3-45 days), 7.85 days (1-130 days) and 6.19 days (1-50 days) for types III, II and I LM, respectively.

Post-operative complications were found in 3/9 (33.3 \%) patients with type III LM, $3 / 49$ (6.1\%) with type II LM and none in patients with type I.

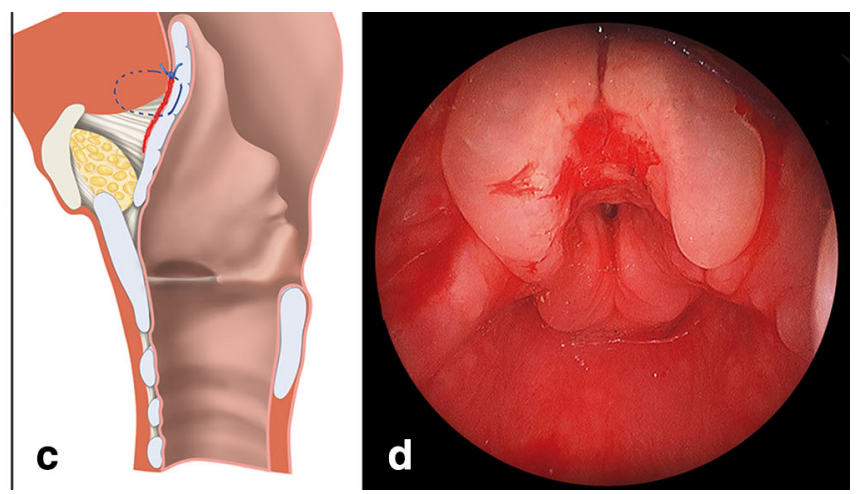

arrows) undergoing $\mathrm{CO}_{2}$ laser-induced mucosal fulguration. c Schematic diagram showing the placement of endoscopic pexy sutures. d Post-operative view showing the epiglottis fixed against the base of tongue and the laryngeal inlet optimally open

Comorbidities were present in $88.9 \%$ (8/9) patients with type III LM, $52.4 \%$ (11/21) patients with type I LM and $51.0 \%(25 / 49)$ with type II LM. In the subset of patients with type III LM, SAL were seen in $88.9 \%(8 / 9)$ patients, neurological comorbidities in $33.3 \%$ (3/9 patients), prematurity in $55.6 \%$ (5/9 patients) and GERD in $44.4 \%$ (4/9 patients). These associations were considerably lower in LM I and II (Table 2).

\section{Discussion}

Our series confirms that LSGP is safe and efficient in severe and symptomatic cases of LM as has been demonstrated in multiple studies [10, 23]. Nevertheless, certain patients presenting with comorbidities such as congenital anomalies, neurological pathologies, prematurity and synchronous airway lesions SAL have less favorable outcomes and more complications. This confirms the findings of previously published works $[17,24]$. Numerous classifications of LM exist [2, 8-12], but few studies [13, 14, 17, 29] have analyzed the outcomes of SGP according to the morphological type of LM.

Our case series included morphological types I, II and III of LM, in 26.6, 62 and $11.4 \%$ of cases, respectively, according to Olneys' classification [9]. The success rate of LSGP for type III was lower ( $66.7 \%, 6 / 9$ patients) than for type I $(90.5 \%, 19 / 21)$ and type II $(87.8 \%, 43 / 49)$. To our knowledge, this is the first report indicating that the morphological type of LM seems to be an independent risk factor for the success or failure after LSGP. Of course, these observations and results need to be confirmed by further prospective studies involving more patients with a multivariate analysis. 
Table 1 Success rate of laser supraglottoplasty (LSGP) with respect to the comorbidities and the subtype of laryngomalacia (LM)

\begin{tabular}{lccc}
\hline & Number of patients & Success rate of LSGP & $p$ value (one-sided Fisher's exact test) \\
\hline All patients & 79 & $68 / 79(86.1 \%)$ & 0.185 \\
With comorbidities & $44(55.7 \%)$ & $36 / 44(81.8 \%)$ & 0.076 \\
Neurological comorbidities & $13(16.5 \%)$ & $9 / 13(69.2 \%)$ & 0.099 \\
Synchronous airway lesions & $26(32.9 \%)$ & $20 / 26(76.9 \%)$ & 0.014 \\
Prematurity & $18(22.8 \%)$ & $12 / 18(66.7 \%)$ & 0.105 \\
GERD & $33(41.8 \%)$ & $26 / 33(78.8 \%)$ & $p$ value (two-sided Fisher's exact test) \\
\hline Subtype of LM & Number of patients & Success rate of LSGP & 0.195 \\
\hline Type I & $21(26.6 \%)$ & $19 / 21(90.5 \%)$ & \\
Type II & $49(62 \%)$ & $43 / 49(87.8 \%)$ & \\
Type III & $9(11.4 \%)$ & $6 / 9(66.7 \%)$ & \\
\hline
\end{tabular}

Table 2 Demography, presenting symptoms, comorbidities, length of hospital stay, complications and outcome of laser supraglottoplasty (LSGP) with respect to the subtype of laryngomalacia (LM)

\begin{tabular}{|c|c|c|c|c|}
\hline & \multicolumn{3}{|l|}{ Subtypes of LM } & \multirow[t]{2}{*}{ All patients } \\
\hline & Type I & Type II & Type III & \\
\hline Patients $n$ & $21(26.6 \%)$ & $49(62 \%)$ & $9(11.4 \%)$ & $79(100 \%)$ \\
\hline Male & $10 / 21(47.6 \%)$ & $30 / 49(61.2 \%)$ & $4 / 9(44.4 \%)$ & $44(55.7 \%)$ \\
\hline Female & $11 / 21(52.4 \%)$ & $19 / 49(38.8 \%)$ & $5 / 9(55.6 \%)$ & $35(44.3 \%)$ \\
\hline Mean age at the time of LSGP (months) & $21.9(0-131)$ & $4.8(0-28)$ & $34.7(3-137)$ & $12.7(0-137)$ \\
\hline \multicolumn{5}{|l|}{ Presenting symptoms } \\
\hline Stridor & $21 / 21(100 \%)$ & $49 / 49(100 \%)$ & $4 / 9(44.4 \%)$ & $74(93.7 \%)$ \\
\hline Chest retractions & $13 / 21(61.9 \%)$ & $40 / 49(81.6 \%)$ & $2 / 9(22.2 \%)$ & $55(69.6 \%)$ \\
\hline Desaturation/cyanosis/apnea & $3 / 21(14.3 \%)$ & $18 / 49(36.7 \%)$ & $1 / 9(11.1 \%)$ & $22(27.8 \%)$ \\
\hline Feeding difficulties/failure to thrive & $5 / 21(23.8 \%)$ & $29 / 49(59.2 \%)$ & $0 / 9(0 \%)$ & $34(43 \%)$ \\
\hline Tracheotomy & $0 / 21(0 \%)$ & $0 / 49(0 \%)$ & $5 / 9(55.6 \%)$ & $5(6.3 \%)$ \\
\hline Comorbidities & $11 / 21(52.4 \%)$ & $25 / 49(51.0 \%)$ & $8 / 9(88.9 \%)$ & $44(55.7 \%)$ \\
\hline Neurological comorbidities & $5 / 21(23.81 \%)$ & $5 / 49(10.2 \%)$ & $3 / 9(33.3 \%)$ & $13(16.5 \%)$ \\
\hline Synchronous airway lesions & $7 / 21(33.3 \%)$ & $11 / 49(22.5 \%)$ & $8 / 9(88.9 \%)$ & $26(32.9 \%)$ \\
\hline Prematurity & $2 / 21(9.5 \%)$ & $11 / 49(22.5 \%)$ & $5 / 9(55.6 \%)$ & $18(22.8 \%)$ \\
\hline GERD & $7 / 21(33.3 \%)$ & $22 / 49(44.9 \%)$ & $4 / 9(44.4 \%)$ & $33(41.8 \%)$ \\
\hline Length of stay in ICU [h (range)] & $30.9(24-96)$ & $52.08(24-360)$ & $42.67(0-168)$ & $45.4(0-360)$ \\
\hline Length of stay in hospital [days (range)] & $6.19(1-50)$ & $7.85(1-130)$ & $11.11(3-45)$ & $7.78(1-130)$ \\
\hline Follow up [months (range)] & $2.52(1-12)$ & $5.02(1-39)$ & $7.67(2-14)$ & $4.7(1-39)$ \\
\hline Complications & $0(0 \%)$ & $3 / 49(6.1 \%)$ & $3 / 9(33.3 \%)$ & $6(7.6 \%)$ \\
\hline \multicolumn{5}{|l|}{ Outcome of LSGP } \\
\hline Success & $19(90.5 \%)$ & $43(87.8 \%)$ & $6(66.7 \%)$ & $68(86.1 \%)$ \\
\hline Failure & $2(9.5 \%)$ & $6(12.2 \%)$ & $3(33.3 \%)$ & $11(13.9 \%)$ \\
\hline
\end{tabular}

Olney's classification is practical and surgically relevant. The surgical intervention differs as per the morphological type of LM. In types I and II, the surgery reduces the redundant supra arytenoid tissues, and corrects the short aryepiglottic folds. In type III LM, the epiglottis needs to be attached to the tongue base to avoid its prolapse into the airway. We found a high rate of pexy breakdown (3 out of 9 cases) after epiglottopexy done conventionally in the earlier part of our study. To resolve this issue, we have developed a new technique for epiglottopexy using the 
Lichtenberger's needle-carrier (LNC) [25], that allows making deeper pexy sutures that are less prone to break down. Under suspension laryngoscopy, a laser-assisted mucosal fulguration of the valleculae and the base of tongue is performed. Then, transfixating sutures are placed transorally between the base of tongue and epiglottis using the LNC. The resorbable sutures are buried in the subcutaneous tissue by a separate external mini skin incision. These glosso-epiglottic sutures are deep enough into the tongue base to successfully fix the epiglottis and keep the laryngeal inlet open (Fig. 4). This technique was not applied to the patients described here but it has recently become the standard procedure for epiglottopexy in our clinic (5 cases in 2015 with $100 \%$ success rate). We believe that in the past treatment for type III LM, the nontransfixant pexy sutures were placed too superficially into the tongue base, and this played an important role in the high failure rate seen. With this new epiglottopexy technique, none of our patients had any neurovascular complications of the tongue or experienced chronic intractable bronchoaspiration.
We also note that patients with type III LM are associated with more comorbidities such as SAL, prematurity and neurological conditions that may have required preoperative tracheotomy (5/9) in comparison to patients with types I and II (Table 2). Needless to say that, these associations played an important role in the poor final result outcomes.

SALs are adverse prognostic indicators as already observed by Schroeder et al. [24]. In our study, there were 26 patients $(32.9 \%)$ suffering from concomitant SALs, which is higher than in most published studies to date [24, 26-28]. This may be explained, by the fact that our clinic treats several patients from foreign countries referred for the treatment of complex airway pathologies and in particular for glotto-subglottic stenoses (GSGS) and consequently our cases often have multiple SALs-which need correction before definitive stenoses treatment. Advanced age of presentation may also be related to the delayed referral of these patients. Additionally, all these patients had dedicated and systematic pre-operative endoscopic work-up (dynamic transnasal flexible bronchoscopy, direct
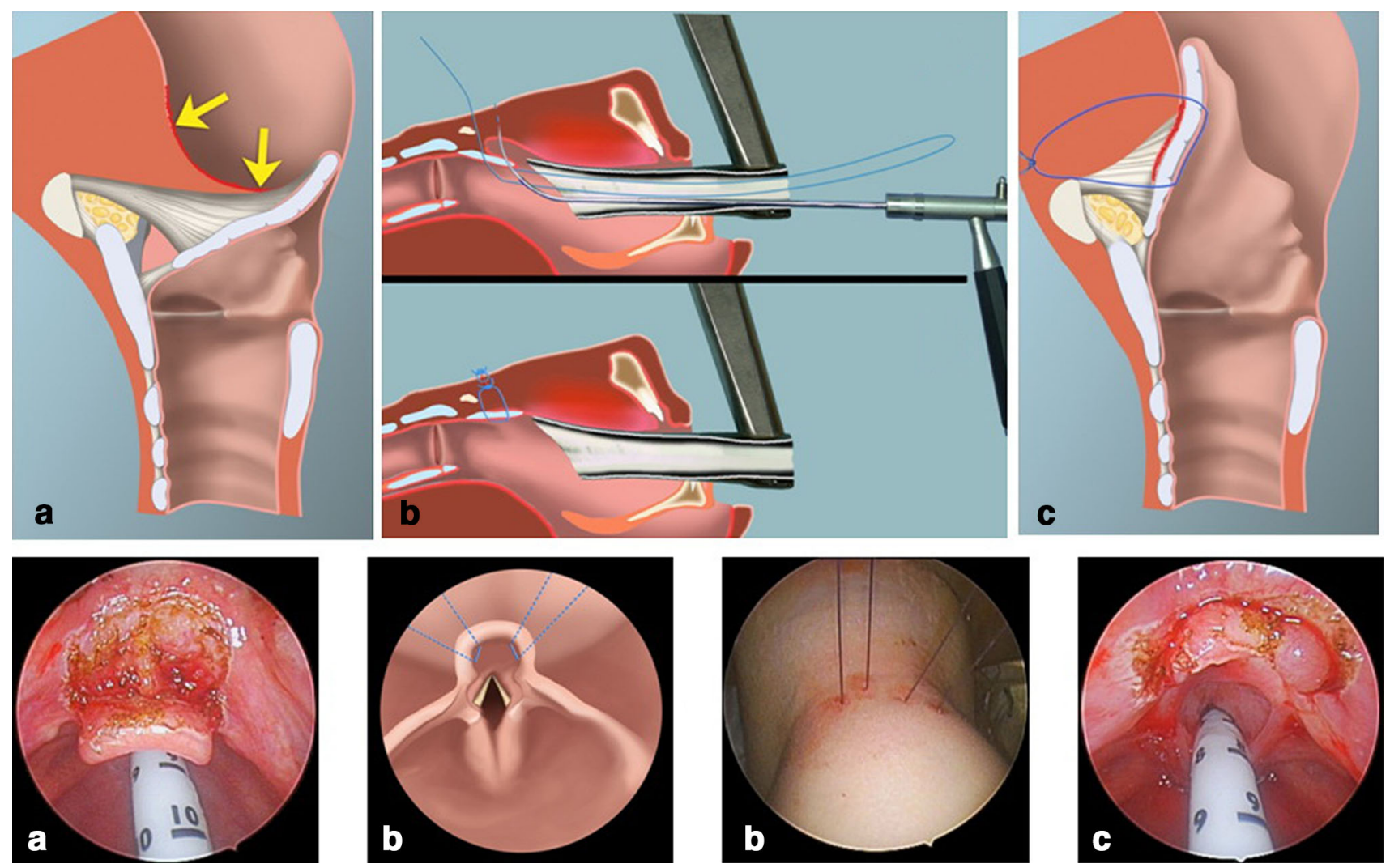

Fig. 4 New epiglottopexy technique using the Lichtenberger's needle-carrier. a Schematic diagram showing $\mathrm{CO}_{2}$ laser fulguration of the base of tongue and lingual aspect of the epiglottis, $\mathbf{b}$ schematic diagram showing suspension laryngoscopy and two transfixating stapler-like sutures that are passed transorally between the base of tongue and epiglottis using the Lichtenberger's needle-carrier. The resorbable sutures are buried in the subcutaneous tissue by a separate external mini skin incision, c schematic diagram and intra operative picture showing the final result with deep sutures holding the epiglottis towards the tongue base and keeping the laryngeal inlet open 
laryngo-tracheoscopy and oesophagoscopy) that allowed better diagnosis of these additional pathologies that were previously missed.

In our study, 44 patients $(55.7 \%)$ presented with comorbidities and showed a lower success rate after SGP and this confirms previously published results $[19,23]$. The success rate of LSGP in premature patients $(66.7 \%$, $12 / 18$ ), is significantly lower than the overall success rate in the present series $(p=0.014)$. This confirms that prematurity is an unfavorable prognostic factor for SGP, and this is in agreement with the literature [10, 18, 23, 24, 29].

The success rate in cases of associated GERD (44 patients) was $81.8 \%(36 / 44)$, which is lower than our overall success rate. This may be explained in part by the persistent pharyngolaryngeal inflammation despite aggressive pre-operative treatment. In the present series, diagnosis of GERD was based on symptoms and confirmed during oesophagoscopy. Pre-treatment of $\mathrm{pH}$-metry is more sensitive and specific in GERD diagnosis, but was not performed in our patients.

Concerning SGP failures, 11 patients needed at least one salvage operation with 15 revision procedures in total. Of the 15 salvage procedures-nine were epiglottopexies and six were supraglottoplasties. An either too conservative or too aggressive excision of the supraglottic tissues leads to recurrence of symptoms. Indeed, symptoms are bound to recur if the causative redundant tissues are insufficiently removed. When too much tissue is excised, aryepiglottic folds are replaced by fibrocicatrical tissue that pulls the epiglottis downwards further blocking the laryngeal inlet and may transform into more dreaded supraglottic stenosis. In such salvage re-do endoscopic surgeries, it is critical to perform: (a) an epiglottopexy using the Lichtenberger's needle-carrier and (b) mobilize the medial piriform sinus mucosae and suture it anteriorly up to the vestibular folds-thus reforming the neo aryepiglottic folds. This leaves very little or no raw area in the supraglottis-thus preventing cicatricial pulling down of the epiglottis.

There are several drawbacks in our study—namely being a retrospective analysis based on clinical presentations and observations during endoscopy. The results need to be confirmed with prospective multi-centric studies involving larger number of patients. We feel that the examination of an awake child done in an outpatient clinic has certain drawbacks - though it is the best way to visualize the upper airway dynamics. With improved anesthesia techniques, the pediatric anesthesiologists of our institution are able to aptly maintain the airway dynamics of a child under general anesthesia, allowing us to evaluate minute details of a floppy airway. Such an examination in an OT set-up eliminates the infants discomfort and the parents stress. Detailed awake and sleep endoscopy of the entire airway can be done during this anesthesia, thus eliminating the effect of troublesome mass pharyngolaryngeal movements that are experienced while examining the child in the outpatient clinic. Additionally, an LSGP can be done if necessary.

\section{Conclusions}

LSGP is effective and safe to treat severe LM. Different morphological types of LM require slight surgical variations of LSGP. Optimal treatment requires accurate diagnosis that is best achieved during dynamic transnasal flexible laryngobronchoscopy with the child breathing spontaneously. Our series confirms that prematurity is a risk factor for SGP failure. Using a treatment-oriented classification, we show that type III LM has an increased risk of failure due to high breakdown rate of epiglottopexy. Also, patients with type III LM have an increased incidence of comorbidities (synchronous airway lesions, prematurity and neurological problems) than patients with types I and II LM and hence have poorer prognosis. Larger prospective studies are required to perform multivariate analysis and definitely prove that type III LM is an independent risk factor for SGP failure. Epiglottopexy sutures using conventional needle-carriers are inadequate and prone to pexy breakdown and treatment failure. Our new technique using the Lichtenberger's needle-carrier has improved our epiglottopexy results.

\section{Compliance with ethical standards}

Funding None.

Conflict of interest The authors declare that they have no conflict of interest.

Ethical approval All procedures performed in this study involving human participants were in accordance with the ethical standards of our institutional research committee and with the 1964 Helsinki declaration and its later amendments or comparable ethical standards.

Informed consent For this type of study (retrospective study) formal consent is not required.

\section{References}

1. Daniel SJ (2006) The upper airway: congenital malformations. Paediatr Respir Rev 7(Suppl 1):S260-S263

2. Kay DJ, Goldsmith AJ (2006) Laryngomalacia: a classification system and surgical treatment strategy. Ear Nose Throat J 5(5):328-331, 336

3. Manning SC, Inglis AF, Mouzakes J, Carron J, Perkins JA (2005) Laryngeal anatomic differences in pediatric patients with severe laryngomalacia. Arch Otolaryngol Head Neck Surg 131(4):340-343

4. Chandra RK, Gerber ME, Holinger LD (2001) Histological insight into the pathogenesis of severe laryngomalacia. Int $\mathbf{J}$ Pediatr Otorhinolaryngol 61(1):31-38 
5. Thompson DM (2007) Abnormal sensorimotor integrative function of the larynx in congenital laryngomalacia: a new theory of etiology. Laryngoscope 117(6 Pt 2 Suppl 114):1-33

6. Bibi H, Khvolis E, Shoseyov D et al (2001) The prevalence of gastroesophageal reflux in children with tracheomalacia and laryngomalacia. Chest 119(2):409-413

7. Hartl TT, Chadha NK (2012) A systematic review of laryngomalacia and acid reflux. Otolaryngol Head Neck Surg 147(4):619-626

8. Roger G, Denoyelle F, Triglia JM, Garabedian EN (1995) Severe laryngomalacia: surgical indications and results in 115 patients. Laryngoscope 105(10):1111-1117

9. Olney DR, Greinwald JH, Smith RJ, Bauman NM (1999) Laryngomalacia and its treatment. Laryngoscope 109(11):1770-1775

10. Lee K-S, Chen B-N, Yang C-C, Chen Y-C (2007) $\mathrm{CO}_{2}$ laser supraglottoplasty for severe laryngomalacia: a study of symptomatic improvement. Int $\mathbf{J}$ Pediatr Otorhinolaryngol 71(6):889-895

11. Holinger LD, Konior RJ (1989) Surgical management of severe laryngomalacia. Laryngoscope 99(2):136-142

12. Shah UK, Wetmore RF (1998) Laryngomalacia: a proposed classification form. Int J Pediatr Otorhinolaryngol 46(1-2):21-26

13. Landry AM, Thompson DM (2012) Laryngomalacia: disease presentation, spectrum, and management. Int $\mathrm{J}$ Pediatr 2012:753526

14. Ayari S, Aubertin G, Girschig H et al (2013) Management of laryngomalacia. Eur Ann Otorhinolaryngol Head Neck Dis 130(1):15-21

15. Richter GT, Thompson DM (2008) The surgical management of laryngomalacia. Otolaryngol Clin N Am 41(5):837-864, vii

16. Toynton SC, Saunders MW, Bailey CM (2001) Aryepiglottoplasty for laryngomalacia: 100 consecutive cases. J Laryngol Otol 115(1):35-38

17. Preciado D, Zalzal G (2012) A systematic review of supraglottoplasty outcomes. Arch Otolaryngol Head Neck Surg 138(8):718-721

18. Day KE, Discolo CM, Meier JD, Wolf BJ, Halstead LA, White DR (2012) Risk factors for supraglottoplasty failure. Otolaryngol Head Neck Surg 146(2):298-301
19. Denoyelle F, Mondain M, Gresillon N, Roger G, Chaudre F, Garabedian EN (2003) Failures and complications of supraglottoplasty in children. Arch Otolaryngol Head Neck Surg 129(10):1077-1080 (discussion 1080)

20. Thompson DM (2010) Laryngomalacia: factors that influence disease severity and outcomes of management. Curr Opin Otolaryngol Head Neck Surg 18(6):564-570

21. Durvasula VSPB, Lawson BR, Bower CM, Richter GT (2014) Supraglottoplasty outcomes in neurologically affected and syndromic children. JAMA Otolaryngol Head Neck Surg 140(8):704-711

22. Escher A, Probst R, Gysin C (2015) Management of laryngomalacia in children with congenital syndrome: the role of supraglottoplasty. J Pediatr Surg 50(4):519-523

23. Senders CW, Navarrete EG (2001) Laser supraglottoplasty for laryngomalacia: are specific anatomical defects more influential than associated anomalies on outcome? Int J Pediatr Otorhinolaryngol 57(3):235-244

24. Schroeder JW, Bhandarkar ND, Holinger LD (2009) Synchronous airway lesions and outcomes in infants with severe laryngomalacia requiring supraglottoplasty. Arch Otolaryngol Head Neck Surg 135(7):647-651

25. Sandu K, Monnier P, Reinhard A, Gorostidi F (2015) Endoscopic epiglottopexy using Lichtenberger's needle carrier to avoid breakdown of repair. Eur Arch Otorhinolaryngol 272(11):3385-3390

26. Gonzalez C, Reilly JS, Bluestone CD (1987) Synchronous airway lesions in infancy. Ann Otol Rhinol Laryngol 96(1 Pt 1):77-80

27. Mancuso RF, Choi SS, Zalzal GH, Grundfast KM (1996) Laryngomalacia. The search for the second lesion. Arch Otolaryngol Head Neck Surg 122(3):302-306

28. Yuen H-W, Tan HK-K, Balakrishnan A (2006) Synchronous airway lesions and associated anomalies in children with laryngomalacia evaluated with rigid endoscopy. Int J Pediatr Otorhinolaryngol 70(10):1779-1784

29. Erickson B, Cooper T, El-Hakim H (2014) Factors associated with the morphological type of laryngomalacia and prognostic value for surgical outcomes. JAMA Otolaryngol Head Neck Surg 140(10):927-933 